\title{
AS PERSPECTIVAS DA REPRESENTAÇÃO SUBSTANTIVA SOBRE A AÇÃO PARLAMENTAR FEMININA NO BRASIL
}

\author{
Ana Paula Cavalcante Limão da Silva ${ }^{1}$
}

\begin{abstract}
Resumo
Este artigo apresenta um mapeamento do perfil parlamentar das deputadas federais brasileiras que assumiram mandatos nas legislaturas de 2003-2007, 2007-2011 e 2011-2015 por meio da análise da produção legislativa dessas mulheres, com destaque à proposição de projetos de leis, a fim de verificar em que medida a atuação parlamentar feminina resulta em uma representação substantiva. Para a construção desta pesquisa, utilizamos uma metodologia quantitativa e qualitativa. A base de dados apresenta as seguintes informações: deputadas federais por legislatura, projetos de leis apresentados por cada uma delas, número de projetos transformados em lei, classificação por área temática e observações complementares. Esse banco de dados foi complementado com a inserção da síntese do conteúdo das ementas dos projetos propostos e o resultado do trâmite legislativo. A coleta dos dados foi realizada no Portal da Câmara dos Deputados e transpostos para o Programa Estatístico SPSS. Evidencia que as parlamentares propõem um número de projetos proporcional aos seus colegas homens, as proposições propostas referem-se as áreas relacionadas ao "cuidado" e, na mesma medida, em áreas "bards", tais como trabalho, economia, finanças e tributação, administração e serviço público. Em relação aos temas com pautas sobre gênero, verifica-se que tratam de assuntos relacionados ao trabalho, a saúde da mulher e violências contra o sexo feminino.

Palavras-Chave: Deputadas Federais brasileiras; Representação substantiva; Comportamento parlamentar feminino.
\end{abstract}

\begin{abstract}
This article presents a mapping of the parliamentary profile of the Brazilian federal deputies who took office in the legislatures of 2003-2007, 2007-2011 and 2011-2015, through the analysis of the legislative production of these women, with emphasis on the proposition of draft laws, the in order to verify to what extent the female parliamentary performance results in a substantive representation. For the construction of this research we used a quantitative and qualitative methodology. The database presents the following information: federal deputies by legislature, draft laws submitted by each one, number of projects transformed into law, classification by thematic area and complementary observations. This database was complemented with the insertion of the synthesis of the content of the menus of the proposed projects and the result of the legislative procedure. Data collection was carried out on the Portal of the Chamber of Deputies and transferred to the SPSS Statistical Program. It shows that parliamentarians propose a number of projects proportional to their male colleagues, the proposed propositions refer to areas related to "care" and to the same extent in "hard" areas, such as work, economics, finance and taxation, administration and public service. In relation to themes with guidelines on gender, it appears that they deal with issues related to work, women's health and violence against women.
\end{abstract}

Key words: Brazilian federal deputies; Substantive representation; Female parliamentary behavior.

\footnotetext{
${ }^{1}$ Doutora em Ciência Política (Ufscar), Mestre em Ciências Sociais (Uem), Bacharelado e Licenciatura em Ciências Sociais (Uem). Professora Universitária e Mentora de Projetos Sociais e Políticas Públicas. Pesquisadora do Projeto Mulheres Eleitas - LAPPCOM - UFRJ. Lattes: lattes.cnpq.br/2252495997852964. Orcid: https://orcid.org/0000-0002-5640-5547. E-mail: paulacavalcante7@ hotmail.com
} 


\section{Resumen}

Este artículo presenta un mapeo del perfil parlamentario de las diputadas federales brasileñas que asumieron en las legislaturas de 2003-2007, 2007-2011 y 2011-2015, a través del análisis de la producción legislativa de estas mujeres, con énfasis en la propuesta de proyectos de ley, con el fin de verificar en qué medida la actuación parlamentaria femenina se traduce en una representación sustantiva. Para la construcción de esta investigación se utilizó una metodología cuantitativa y cualitativa. La base de datos presenta la siguiente información: diputados federales por legislatura, anteproyectos de ley presentados por cada uno de ellos, número de proyectos transformados en ley, clasificación por áreas temáticas y observaciones complementarias. Esta base de datos se complementó con la inserción de la síntesis del contenido de los menús de los proyectos propuestos y el resultado del procedimiento legislativo. La recolección de datos se realizó en el Portal de la Cámara de Diputados y se transfirió al Programa Estadístico SPSS. Muestra que los parlamentarios proponen una cantidad de proyectos proporcional a sus colegas masculinos, las propuestas propuestas se refieren a áreas relacionadas con el "cuidado" y en la misma medida en áreas "hards", como trabajo, economía, finanzas y tributación, administración y servicio público. En relación a los temas con lineamientos de género, parece que tratan temas relacionados con el trabajo, la salud de la mujer y la violencia contra la mujer.

Palabras-clave: diputados federales brasileños; Representación sustantiva; Comportamiento parlamentario femenino.

\section{INTRODUÇÃO}

No Brasil, o direito ao voto feminino foi conquistado em 1932, por meio da promulgação do novo Código Eleitoral. Em um primeiro momento, o voto foi restringido às mulheres casadas, com autorização de seus maridos, ou viúvas e solteiras com renda própria. Em 1934, a Assembleia Nacional Constituinte reiterou o direito ao voto feminino, abolindo as restrições promulgadas anteriormente e tornou o voto obrigatório apenas para as mulheres que desempenhassem alguma função remunerada em cargos públicos. Assim, a obrigatoriedade para todas as mulheres foi instituída na Constituição de 1946.

A tímida representação das mulheres no Parlamento no mundo inicia-se no século XX. De acordo com Alves (2006), um número de 10 países apresentava representação parlamentar feminina até a década de 1930. O autor argumenta que o crescimento feminino no legislativo ocorreu após o fim da Segunda Guerra Mundial, motivado pela criação da Organização das Nações Unidas (ONU), em 1945, e a aprovação da Declaração Universal dos Direitos Humanos, em 1948, que proíbe qualquer discriminação de raça, etnia, nacionalidade, idade e gênero.

O século XXI inicia-se com uma situação favorável para a participação política feminina no parlamento, no entanto, é baixa a presença de mulher ocupando esse cargo eletivo em diversos países pelo mundo. De acordo com Silva (2006), após a Segunda Guerra Mundial, aumentou o número de países com parlamento pelo mundo, dados do IPU indicam que, em 1945, eram 26 parlamentos, esse número elevou-se para 187 parlamentos até 2005. 
Os dados da IPU ${ }^{2}$ mostram que a média global de mulheres nos parlamentos nacionais, em 2016, é de 23,3\%. A instituição também apresenta o percentual da representação feminina em Parlamento no mundo com base em informações fornecidas até 1 de fevereiro de 2019, 193 países são classificados na pesquisa. Assim, os dez países com maior percentual de mulheres ocupando uma cadeira no legislativo são respectivamente: Ruanda (África) 61,3\%, Cuba (América do Norte) 53,2\%, Bolívia (América do Sul) 53,1\%, México (América do Norte) 48,2\%, Suécia (Europa) 47,3\%, Granada (América do Norte) 46,7\%, Namíbia (África) 46,2\%, Costa Rica (América do Norte) $45,6 \%$ e África do Sul (África) 42,7\%. Nesse contexto, os continentes com maior representatividade feminina são África e América do Norte.

De acordo com os dados do IPU ${ }^{3}$ (Relatório sobre Mulheres no Parlamento em 2016), destaca que os países do continente Africano, das Américas e da Europa que adotam as políticas de cotas apresentam um aumento no número de representantes mulheres na política. No caso africano, a expressiva presença feminina nos parlamentos indica uma maior abertura para a participação política nesses países.

Segundo o $\mathrm{TSE}^{4}$, as mulheres brasileiras representam 52\% do eleitorado, mas ainda são minoria no espaço político. Os dados do IPU, em 2019, indicam que o país está na $132^{a}$ posição com um percentual de 15\% de representatividade feminina no Parlamento, por isso, é um desafio superar a baixa representatividade feminina na política.

Os estudos de Pinheiro (2006) e Sacchet (2009) elucidam aspectos sobre a baixa presença feminina na política, apontando que as dificuldades das mulheres nesse espaço iniciam-se na candidatura à eleição. Desse modo, a presença de mulheres em grupos, em movimentos sociais e em partidos pode contribuir para a sua entrada na política e, assim, aproximá-las da Casa Legislativa.

Sacchet (2009) afirma que os principais fatores que interferem na sub-representação feminina são os de ordem cultural, social e institucional. Em relação aos fatores de ordem cultural, a sociedade ainda tem dificuldade em promover uma maior abertura política para as mulheres, a figura feminina está relacionada ao ambiente privado, com destaque para as áreas do cuidado e gênero. O fator social está vinculado à escolaridade, profissão e estado civil, os quais interferem na

\footnotetext{
${ }^{2}$ Inter-Parliamentary Union (IPU). Disponível em < http://www.ipu.org/wmn-e/classif.htm> em 1 fev. 2019. Acesso em 3 jul. 2019.

3 Inter-Parliamentary Union (IPU). Disponível em < https://www.ipu.org/news/press-releases/2017-03/ em 15 mar.2017. Acesso em 3 jul. 2019.

${ }^{4}$ Tribunal Superior Eleitoral (TSE). Disponível em http://www.tse.jus.br
} 
chegada da mulher na política. Finalmente, o fator institucional considera as dificuldades da mulher desde a candidatura até a eleição, como também em se manter em um cargo eletivo.

A política afirmativa das cotas tem contribuído para os avanços da presença da mulher em cargos eletivos no mundo. O principal objetivo das cotas é reservar um número de candidaturas femininas a fim de atenuar o gap existente entre os sexos. Essa política foi adotada no final dos anos de 1970 nos países do norte da Europa.

No Brasil, a política de cotas entrou em vigor nas eleições municipais de 1996 e nas eleições estaduais e federais de 1998. No final de 1997, com a aprovação da nova lei eleitoral de $n^{\circ} 9504$, que determinou a reserva de vagas como cotas, definiu-se que, nas eleições de 1998 para deputados estaduais e federais, as cotas seriam de $25 \%$ como mínimo a ser preenchido para cada sexo. Nas eleições seguintes, o percentual mínimo deveria ser de 30\%. Nesse sistema, os partidos seriam obrigados a respeitar o percentual mínimo de reserva e não poderiam ocupar a vaga com candidatos do outro sexo, porém não seriam obrigados a preenchê-las integralmente com candidatos do mesmo sexo.

Araújo (2009) analisa a relação da sub-representação feminina e os resultados das cotas no Brasil. A autora evidencia que a política afirmativa de cotas passa por três momentos, ou seja, a sua implementação, seus impactos e os seus resultados. Nesse contexto, no caso brasileiro, a adoção é parcial e o impacto é baixo. Na verdade, a política de cotas envolve uma relação de causa e efeito entre a forma de representação descritiva e substantiva.

Para Sanchez (2015), a implantação da política de cotas possibilitou um aumento no número de candidaturas femininas, o que, contudo, não elevou o número de mulheres eleitas. A autora aponta que a mulher enfrenta dificuldades tanto para lançar a sua candidatura quanto para se eleger, justificando que "a porcentagem de mulheres no parlamento é um indicador importante na avaliação da qualidade da democracia” (SANCHEZ, 2015, p. 01).

Segundo Franceschet (2008), o comitê de mulheres pode reforçar a solidariedade por gênero e desenvolver estratégias em relação a iniciativas legislativas. Na América Latina, essas inciativas ocorrem na bancada feminina brasileira e uruguaia. A autora acrescenta que o movimento de mulheres contribui para promover questões de gênero, pois incentiva as deputadas a propor projetos sobre os direitos da mulher.

A representação substantiva feminina está ampliando o campo de atuação na política, no caso das deputadas, além de buscar identificar o quanto elas estão sendo substantivas em relação aos temas sobre gênero, faz-se necessário observar se elas estão promovendo debates que as envolvam em tomadas de decisão no parlamento. Conforme essas mulheres avançam suas 
atividades parlamentares em áreas relacionadas ao universo masculino, elas conseguem se envolver de maneira mais efetiva nos processos de tomada de decisão.

O Congresso Nacional brasileiro é composto pela Câmara dos Deputados e pelo Senado Federal. As principais atividades dos deputados e senadores consistem em legislar e fiscalizar os demais poderes (executivo e judiciário). De modo geral, as áreas do Parlamento consistem em representação, legislação, controle do Executivo e legitimação. Segundo Cotta (1998, p. 880), o Parlamento pode definir-se como:

\begin{abstract}
Uma assembleia ou um sistema de assembleias baseadas num "princípio representativo", que é diversamente especificado, mas determina os critérios da sua composição. Estas assembleias gozam de atribuições funcionais variadas, mas todas elas se caracterizam por um denominador comum: a participação direta ou indireta, muito ou pouco relevante, na elaboração e execução das opções políticas, a fim de que elas correspondam à "vontade popular".
\end{abstract}

Quanto ao número de parlamentares por sexo entre titulares, suplentes e efetivos, identificamos, na legislatura de 2003 a 2007, 52 mulheres e 577 homens; de 2007 a 2011,52 mulheres e 584 homens e, de 2011 a 2015, 60 mulheres e 531 homens. Assim, há um percentual aproximado de $10 \%$ de mulheres e $90 \%$ de homens no Parlamento brasileiro no período considerado neste estudo. Nesse contexto, ao investigar a atuação das deputadas, emerge uma discussão tradicional do comportamento legislativo, porém contemporânea para o debate sobre gênero na política, pois há uma gama de estudos sobre a participação política feminina, mas há poucas análises que abordam a atuação parlamentar da mulher e os seus desdobramentos na Casa Legislativa.

2. PROJETOS DE LEIS COM AUTORIA FEMININA NAS LEGISLATURAS DE 2003 A 2015

A presença da mulher brasileira no Parlamento é baixa, mas é possível identificar um aumento de deputadas eleitas e exercendo seus mandatos nas legislaturas de 1990 a 2019. Os dados do IPU ${ }^{5}$ mostram o percentual de mulheres no Parlamento brasileiro de 1990, 2000 e 2010: na

${ }^{5}$ Inter-Parliamentary Union (IPU). Disponível em < https://www.ipu.org/news/press-releases/2017-03/ em mar. 2019. Acesso em 14 jul. 2019. 
legislatura de 1995 a 1999 (6,6\%), 1999 a 2003 (6,8\%), 2003 a 2007 (8,6\%), e 2007 a 2011 (8,6\%), 2011 a $2015(9,9 \%), 2015$ a $2019(10,7 \%)$ e 2019 a 2023, (15\%).

Esta seção indica os dados sobre a produção legislativa feminina, com foco nos projetos de leis propostos pelas deputadas consideradas neste estudo, em que considera a quantidade de projetos apresentados, estado de origem das parlamentares, partido das parlamentares, se trata-se de proposta individual da deputada ou apresentado em coautoria, os temas das propostas e o resultado do trâmite de tais projetos.

Nas tabelas que apresentam a variável projetos propostos, considerou-se um total de 148 parlamentares que apresentaram esse tipo de proposição. É importante mencionar que, na legistura de 2003-2007, quatro deputadas não propuseram projetos de leis durante seus mandatos, em 20072011, foram seis deputadas e, em 2011-2015, também seis deputadas. Assim, soma-se 16 parlamentares nas três legislaturas que não apresentaram propostas dessa natureza, entre os motivos destaca-se: 10 deputadas assumiram como suplente por um curto período de tempo, o que pode ter influenciado para a não proposição de projetos, quatro deputadas licenciaram-se do mandato, uma deputada assumiu como suplente por um curto período e no final da legislatura retornou como efetivada e uma deputada efetivada no final da legistura.

A tabela 1 indica o número de projetos propostos por mulheres e homens nas legislaturas 2003-2007, 2007-2011 e 2011-2015.

Tabela 1 - Distribuição de projetos de leis por gênero pelas legislaturas de 2003-2007, 2007-2011 e 2011-2015

\begin{tabular}{c|c|c|c|c|c|c}
\hline \multirow{2}{*}{ Projetos por gênero } & \multicolumn{9}{|c}{ LEGISLATURAS } \\
\cline { 2 - 7 } & \multicolumn{2}{|c|}{$2003-2007$} & $2007-2011$ & \multicolumn{2}{|c}{$2011-2015$} \\
\cline { 2 - 7 } & $\mathrm{N}$ & $\%$ & $\mathrm{~N}$ & $\%$ & $\mathrm{~N}$ & $\%$ \\
\hline Projetos propostos por mulheres & 709 & 9 & 710 & 9 & 948 & 11 \\
Projetos propostos por homens & 7001 & 91 & 7344 & 91 & 7442 & 89 \\
\hline Total de projetos & 7710 & 100 & 8054 & 100 & 8390 & 100 \\
\hline
\end{tabular}

Fonte: Elaborada pela autora com dados do portal do Congresso Nacional. Acesso set. 2018.

A tabela 1 aponta que as mulheres propuseram 709 projetos na legislatura 2003-2007, 710 projetos na legislatura 2007-2011 e 948 projetos na legislatura 2011-2015, um total de 2.367 projetos propostos nas três legislaturas. Nesse contexto, em termo de percentual, $90 \%$ dos projetos foram propostos por homens e 10\% deles foram propostos por mulheres. Diante disso, observase a existência de um equilíbrio no número de proposições para ambos os sexos, o que indica que 
as deputadas estão ativas nessa atividade tanto quanto os seus colegas homens.

Os dados abaixo mostram o número agregado pelas três legislaturas de projetos propostos por deputada. É importante registrar que, no caso das mulheres reeleitas, considera-se a soma total do número de proposições propostas nas legislaturas em que a parlamentar assumiu mandato. Conforme a tabela a seguir.

Tabela 2 - Projetos propostos por deputada agregados das legislaturas

\begin{tabular}{|c|c|c|}
\hline Deputadas & $\begin{array}{c}\mathrm{N} \text { de projetos } \\
\text { propostos }\end{array}$ & $\%$ \\
\hline Alice Portugal - PCdoB/BA & 67 & 3 \\
\hline Aline Corrêa - PP/SP & 35 & 2 \\
\hline Almerinda de Carvalho - PMDB/RJ & 13 & 1 \\
\hline Ana Alencar - PSDB /TO & 1 & 0 \\
\hline Ana Arraes - PSB/PE & 9 & 0 \\
\hline Andreia Zito - PSDB/RJ 23 & 71 & 3 \\
\hline Angela Amin - PP/SC & 4 & 0 \\
\hline Angela Guadagnin - PT/SP & 13 & 1 \\
\hline Angela Portela - PT/RR & 6 & 0 \\
\hline Ann Pontes - PMDB/PA & 31 & 1 \\
\hline Antônia Lúcia - PSC/AC & 3 & 0 \\
\hline Bel Mesquita - PMDB/PA & 8 & 0 \\
\hline Benedita da Silva - PT/RJ & 19 & 1 \\
\hline Bruna Furlan - PSDB/SP & 24 & 1 \\
\hline Carmen Zanatto - PPS/SC & 23 & 1 \\
\hline Celcita Pinheiro - PFL/MT & 11 & 1 \\
\hline Celia Rocha - PTB/AL & 1 & 0 \\
\hline Cida Borghetti - PROS/PR & 9 & 0 \\
\hline Cida Diogo - PT/RJ & 20 & 1 \\
\hline Dalva Figueiredo - PT/AP & 10 & 0 \\
\hline Dra. Clair - PT/PR & 24 & 1 \\
\hline Dra. Elaine Abissamra - PSB/SP & 1 & 0 \\
\hline Edna Macedo - PTB/SP & 5 & 0 \\
\hline Elcione Barbalho - PMDB/PA & 41 & 2 \\
\hline Eliane Rolim - PT/RJ & 11 & 1 \\
\hline Emilia Fernandes - PT/RS & 1 & 0 \\
\hline Erika Kokay - PT/DF & 89 & 4 \\
\hline Fátima Bezerra - PT/RN & 36 & 2 \\
\hline Fatima Pelaes - PMDB/AP & 21 & 1 \\
\hline Flávia Morais - PDT/GO & 48 & 2 \\
\hline Francisca Trindade - PT/PI & 3 & 0 \\
\hline Gisela Sequeira - PSDB/PA & 1 & 0 \\
\hline Gorete Pereira - PR/CE 123 & 71 & 3 \\
\hline Iara Bernardi - PT/SP & 38 & $\begin{array}{c}2 \\
\text { (Continua) }\end{array}$ \\
\hline
\end{tabular}




\begin{tabular}{|c|c|c|}
\hline Deputadas & $\begin{array}{l}\mathrm{N} \text { de projetos } \\
\text { propostos }\end{array}$ & $\begin{array}{c}\text { (Continuação) } \\
\%\end{array}$ \\
\hline Iriny Lopes - PT/ES & 39 & 2 \\
\hline Íris de Araújo - PMDB/GO & 9 & 0 \\
\hline Jandira Feghali - PCdoB/RJ & 31 & 1 \\
\hline Janete Capiberibe - PSB/AP & 24 & 1 \\
\hline Janete Rocha Pietá - PT/SP & 27 & 1 \\
\hline Jaqueline Roriz - PMN/DF & 19 & 1 \\
\hline Jô Morães - PCdoB/MG & 39 & 2 \\
\hline Juíza Denise Frossard - PPS/RJ & 18 & 1 \\
\hline Jusmari Oliveira - PR/BA & 8 & 0 \\
\hline Kátia Abreu - PFL/TO & 12 & 1 \\
\hline Keiko Ota - PSB/SP & 30 & 1 \\
\hline Kelly Moraes - PTB/RS & 1 & 0 \\
\hline Laura Carneiro - PFL/RJ & 72 & 3 \\
\hline Lauriete - PSC/ES & 18 & 1 \\
\hline Lídice da Mata - PSB/BA & 10 & 0 \\
\hline Liliam Sá - DEM, PFL/RJ & 24 & 1 \\
\hline Lucenira Pimentel - PR/AP & 3 & 0 \\
\hline Luci Choinacki - PT/SC & 24 & 1 \\
\hline Lúcia Braga - PMDB/PB & 4 & 0 \\
\hline Luciana Costa $-\mathrm{PR} / \mathrm{SP}$ & 12 & 1 \\
\hline $\begin{array}{c}\text { Luciana Genro - PT, SEM PARTIDO, } \\
\text { PSOL/RJ }\end{array}$ & 34 & 1 \\
\hline Luciana Santos - PCdoB/PE & 12 & 1 \\
\hline Luiza Erundina - PSB, PT/SP & 32 & 1 \\
\hline Magda Mofatto - PR/GO & 3 & 0 \\
\hline Maninha - PT, PSOL/DF & 43 & 2 \\
\hline Manuela D'avila - PCdoB/RS & 50 & 2 \\
\hline Mara Gabrilli - PSDB/SP & 29 & 1 \\
\hline Maria do Carmo Lara - PT, PMDB/MG & 5 & 0 \\
\hline Maria do Rosário - PT/RS & 43 & 2 \\
\hline Maria Helena - PSB/RR & 6 & 0 \\
\hline Maria Lucia - PMDB/RJ & 2 & 0 \\
\hline Maria Lúcia Cardoso PMDB/MG & 16 & 1 \\
\hline Maria Lúcia Prandi - PT/SP & 12 & 1 \\
\hline Mariangela Duarte - PT/SP & 30 & 1 \\
\hline Marina Meggessi - PPS/RJ & 4 & 0 \\
\hline Marina Santana - PT/GO & 13 & 1 \\
\hline Marinha Raupp - PMDB/RO & 29 & 1 \\
\hline Mirian Reid - PSB/RJ & 1 & 0 \\
\hline Neyde Aparecida - PT/GO & 4 & 0 \\
\hline Nice Lobão - PFL, DEM, PSD/MA & 8 & 0 \\
\hline Nilda Gondim - PMDB/RO & 36 & 2 \\
\hline Nilmar Ruiz - DEM, PFL/TO & 6 & 0 \\
\hline
\end{tabular}

(Continua) 


\begin{tabular}{|c|c|c|}
\hline Deputadas & $\begin{array}{c}\mathrm{N} \text { de projetos } \\
\text { propostos }\end{array}$ & $\begin{array}{l}(\mathrm{Co} \\
\%\end{array}$ \\
\hline Prof. Raquel Teixeira - PSDB/GO & 22 & 1 \\
\hline Professora Dorinha S. Rezende - DEM/TO & 23 & 1 \\
\hline Professora Raquel Teixeira & 13 & 1 \\
\hline Professora Marcivania - PT/AP & 1 & 0 \\
\hline Rebecca Garcia - PP/AM & 46 & 2 \\
\hline Rita Camata - PSDB/ES & 17 & 1 \\
\hline Romanna Remor - PMDB/SC & 1 & 0 \\
\hline Rosane Ferreira - PV/PR & 21 & 1 \\
\hline Rose de Freitas - PMDB/ES & 42 & 2 \\
\hline Rosinha da Adefal - PTdoB/AL & 23 & 1 \\
\hline Sandra Rosado - PSB/RN 123 & 138 & 6 \\
\hline Selma Schons - PT/PR & 25 & 1 \\
\hline Socorro Gomes - PCdoB/PA & 15 & 1 \\
\hline Solange Almeida - PMDB/RJ & 20 & 1 \\
\hline Solange Amaral - DEM/RJ & 27 & 1 \\
\hline Sueli Vidigal - PDT/ES 23 & 83 & 4 \\
\hline Suely - PR/RJ & 1 & 0 \\
\hline Suely Campos - PP/RR & 2 & 0 \\
\hline Telma de Souza - PT/SP & 18 & 1 \\
\hline Teresa Surita - PMDB/RR & 7 & 0 \\
\hline Terezinha Fernandes - PT/MA & 6 & 0 \\
\hline Teté Bezerra - PMDB/MT & 7 & 0 \\
\hline Thelma de Oliveira - PSDB/MT & 19 & 1 \\
\hline Tonha Magalhães - PR/BA & 5 & 0 \\
\hline Vanessa Grazziotin - PcdoB/AM & 79 & 3 \\
\hline Yeda Crusius - PSDB/RS & 7 & 0 \\
\hline Zelinda Novaes - PFL/BA & 13 & 1 \\
\hline Zulaiê Cobra - PSDB/SP & 5 & 0 \\
\hline Total & 2377 & 100 \\
\hline
\end{tabular}

Fonte: Elaborada pela autora com dados do portal do Congresso Nacional. Acesso set. 2018.

Com base nos dados da tabela 2, destaca-se 10 deputadas com maior número de projetos propostos pelas três legislaturas: Alice Portugal - PCdoB/BA com 67 projetos, Andreia Zito PSDB/RJ com 71 projetos, Érika Kokay - PT/ DF com 89 projetos, Gorete Pereira - PR/CE com 71 projetos, Laura Carneiro - PFL/RJ com 72 projetos, Manuela D'avila - PCdoB com 50 projetos, Perpétua Almeida - PCdoB/AC com 59 projetos, Sandra Rosado - PSB/RN com 138 projetos, Sueli Vidigal - PDT/ES com 83 projetos e Vanessa Grazziotin - PCdoB/AM com 79 projetos.

Um fator que interfere no aumento da produção legislativa é a reeleição, entre essas parlamentares 7 delas foram reeleitas em pelo menos uma legislatura deste estudo. Ressalta-se aquelas, que, em uma legislatura, apresentaram um número relevante de projetos, como Érika 
Kokay, Laura Carneiro e Manuella D avila. Em relação ao conteúdo dessas proposições, evidenciase uma diversidade de temas que serão abordados nesta seção.

A tabela a seguir mostra o número de projetos propostos agregados nas três legislaturas por partidos das deputadas consideradas neste estudo.

Tabela 3 - Projetos propostos agregados das legislaturas por partido e gênero

\begin{tabular}{|c|c|c|c|c|c|}
\hline \multirow[t]{2}{*}{ Partidos } & \multirow[t]{2}{*}{$\mathrm{N}$ de projetos } & \multicolumn{2}{|c|}{$\begin{array}{c}\text { Projetos com autoria } \\
\text { feminina }\end{array}$} & \multicolumn{2}{|c|}{ Projetos com autoria masculina } \\
\hline & & $\mathrm{N}$ & $\%$ & $\mathrm{~N}$ & $\%$ \\
\hline DEM & 2514 & 26 & 1 & 2488 & 99 \\
\hline PCdoB & 1161 & 352 & 30 & 809 & 70 \\
\hline PDT & 1711 & 131 & 8 & 1580 & 92 \\
\hline PEN & 16 & 1 & 6 & 15 & 94 \\
\hline PFL & 1118 & 146 & 13 & 972 & 87 \\
\hline PL & 1096 & 22 & 2 & 1074 & 98 \\
\hline PMDB & 5310 & 321 & 6 & 4989 & 94 \\
\hline PMN & 252 & 21 & 8 & 231 & 92 \\
\hline PP & 2234 & 135 & 6 & 2099 & 94 \\
\hline PPS & 1255 & 48 & 4 & 1207 & 96 \\
\hline PR & 1798 & 100 & 6 & 1698 & 94 \\
\hline PRONA & 87 & 1 & 1 & 86 & 99 \\
\hline PROS & 95 & 5 & 5 & 90 & 95 \\
\hline PSB & 2059 & 225 & 11 & 1834 & 89 \\
\hline PSC & 1223 & 21 & 2 & 1202 & 98 \\
\hline PSD & 657 & 13 & 2 & 644 & 98 \\
\hline PSDB & 3583 & 191 & 5 & 3392 & 95 \\
\hline PSOL & 246 & 33 & 13 & 213 & 87 \\
\hline PT & 5856 & 526 & 9 & 5330 & 91 \\
\hline PTB & 1407 & 7 & 0 & 1400 & 100 \\
\hline PT do B & 147 & 23 & 16 & 124 & 84 \\
\hline PV & 1050 & 21 & 2 & 1029 & 98 \\
\hline Sem Partido & 66 & 8 & 12 & 58 & 88 \\
\hline
\end{tabular}

Fonte: Elaborada pela Autora com base no portal do Congresso Nacional, acesso em 29 set. 2018.

A tabela 3 indica que, ao comparar o número de projetos propostos por mulheres e homens pertencentes ao mesmo partido, verifica-se que 30\% dos projetos do PCdoB são de autoria feminina. Em relação ao PT, apesar de ser o partido com o maior número de deputadas eleitas, as proposições com autoria feminina são de apenas $9 \%$ e o PMDB de $6 \%$. Os parlamentares do sexo masculino são mais ativos nessa atividade, o que indica que as deputadas enfrentam obstáculos a serem superados no interior dos seus próprios partidos para elas possam propor projetos de maneira mais igualitária em relação aos seus colegas do sexo masculino. 
A tabela 4 mostra com quem as mulheres estão propondo projetos, ou seja, o número de projetos propostos pelas deputadas por tipo de autoria, se a deputada foi a autora, autora com coautoria, ou coautora.

Tabela 4 - Projetos propostos pelas deputadas agregados das legislaturas por tipo de autoria

\begin{tabular}{c|c|c}
\hline Tipo de autoria & N de Projetos & $\%$ \\
\hline Autora & 2014 & 85 \\
Autora com coautoria & 167 & 7 \\
Coautora & 186 & 8 \\
\hline Total & 2367 & 100 \\
\hline
\end{tabular}

Fonte: Elaborada pela autora com dados do portal do Congresso Nacional. Acesso set. 2018.

A Tabela 4 indica que as deputadas propuseram 2.014 projetos como autora, o que representa $85 \%$ das suas proposições. As parlamentares estão atuando de forma autônoma no processo legislativo, buscam elaborar, apresentar e monitorar os seus projetos de leis de maneira independente. Logo, esse dado indica que as deputadas que ocupam um cargo legislativo apesar da sub-representação não se intimidam em atuar em um espaço, dito masculino, e estão buscando exercer suas atividades mesmo que seja de maneira individual, com obstáculos a serem superados por essas representantes.

As informações a seguir indicam os temas em geral abordados pelos projetos de leis das deputadas consideradas neste estudo. Para a elaboração da classificação temática, considerou-se a ementa dos projetos e, quando não encontrava clareza nesse texto, buscou-se o conteúdo na íntegra da proposição, como também as comissões que realizaram a análise da matéria, conforme a tabela abaixo:

Tabela 5 - Projetos propostos pelas deputadas agregados das legislaturas por área temática

\begin{tabular}{c|c|c}
\hline Áreas temáticas & $\begin{array}{c}\text { N de } \\
\text { Projetos }\end{array}$ & $\%$ \\
\hline Trabalho & 332 & 14 \\
Outros (datas comemorativas, homenagens, denominações) & 192 & 8 \\
Economia, Finanças e Tributação & 185 & 8 \\
Educação & 181 & 8 \\
Saúde & 157 & 7 \\
Administração e serviço público & 134 & 6 \\
Criança e adolescente & 123 & 5 \\
Código Penal e Violências & 112 & 5 \\
Meio Ambiente & 97 & 4 \\
& & (Contínua)
\end{tabular}




\begin{tabular}{c|c|c} 
& & (Continuação) \\
\hline Áreas temáticas & $\begin{array}{c}\text { N de } \\
\text { Projetos }\end{array}$ & $\%$ \\
\hline Código de Trânsito, viação e transporte & 95 & 4 \\
Código eleitoral, org. partidária, referendos e plebiscitos & 89 & 4 \\
Comunicações e informática & 81 & 3 \\
Pessoas com deficiência & 72 & 3 \\
Segurança Pública & 69 & 3 \\
Assistência Social & 68 & 3 \\
Gênero & 65 & 3 \\
Idosos & 55 & 2 \\
Cultura & 50 & 2 \\
Questões rurais e de terras & 46 & 2 \\
Consumidor & 44 & 2 \\
Direitos humanos & 28 & 1 \\
Código Civil & 26 & 1 \\
Esporte & 21 & 1 \\
Minas e Energia & 19 & 1 \\
Moradia & 12 & 1 \\
Questões Raciais e Étnicas & 10 & 0 \\
Religião & 4 & 0 \\
Total & 2367 & 100 \\
\hline
\end{tabular}

Fonte: Elaborada pela autora com dados do portal do Congresso Nacional. Acesso set. 2018.

A Tabela 5 demonstra que há um total de 27 temas abordados pelas proposições, as áreas que se destacam com maior percentual de projetos são 14\% Trabalho, 8\% outros (datas comemorativas, homenagens, denominações), $8 \%$ economia, finanças e tributação, 8\% educação, $7 \%$ saúde, $6 \%$ administração e serviço público, 5\% crianças e adolescente e 5\% código penal e violências. As áreas "hards" como do trabalho, economia finanças e tributação e administração e serviço público, somam $28 \%$ de projetos propostos pelas deputadas. As áreas do "cuidado" como da educação, saúde, criança e adolescente e código penal e violência, somam 25\% de projetos propostos pelas parlamentares. Esses percentuais mostram que as mulheres, além de atuar nas áreas do "cuidado", estão percorrendo novos caminhos com destaque para a atuação nas áreas "bards", o que reflete de maneira positiva para a representação substantiva delas na Câmara Legislativa Federal, como também em fomentar o debate feminino em áreas ditas masculinas.

A presente pesquisa identificou a situação dos projetos de leis propostos pelas deputadas nas legislaturas consideradas, conforme a tabela a seguir: 
Tabela 6 - Projetos propostos pelas deputadas agregados das legislaturas por situação

\begin{tabular}{c|c|c}
\hline Situação & N de Projetos & $\%$ \\
\hline Arquivado & 1281 & 54 \\
Em tramitação & 982 & 41 \\
Transformado em norma jurídica & 104 & 4 \\
\hline Total & 2367 & 100 \\
\hline
\end{tabular}

Fonte: Elaborada pela autora com dados do portal do Congresso Nacional. Acesso set. 2018.

A Tabela 6 aponta um percentual de 54\% dos projetos apresentados pelas deputadas arquivados, $41 \%$ em tramitação e 4\% transformados em normas jurídicas. Esses dados indicam que a maior parte das proposições não se transforma em lei e a tramitação de um projeto proposto por um parlamentar pode levar anos, não sendo definida na legislatura a qual ela foi apresentada.

A tabela a seguir mostra a associação entre área temática e projetos aprovados (transformados em norma jurídica).

Tabela 7 - Projetos propostos pelas deputadas e aprovados agregados das legislaturas por área temática

\begin{tabular}{c|c|c}
\hline $\begin{array}{c}\text { Áreas temáticas dos projetos } \\
\text { propostos pelas deputadas }\end{array}$ & $\begin{array}{c}\text { N de Projetos } \\
\text { aprovados }\end{array}$ & $\%$ \\
\hline Administração e serviço público & 3 & 3 \\
Assistência Social & 1 & 1 \\
Código Civil & - & - \\
Código de Trânsito, viação e transporte & 2 & 2 \\
Código eleitoral, org. partidária, referendos e plebiscitos & 2 & 2 \\
Código Penal e Violências & 4 & 4 \\
Comunicações e informática & - & - \\
Consumidor & - & - \\
Criança e adolescente & 6 & 6 \\
Cultura & 21 & 20 \\
Direitos humanos & - & - \\
Economia, Finanças e Tributação & 2 & 2 \\
Educação & 6 & 6 \\
Esporte & 1 & 1 \\
Gênero & 3 & 3 \\
Idosos & 3 & 3 \\
Meio Ambiente & - & - \\
Minas e Energia & - & - \\
Moradia & - & - \\
Questões Raciais e Étnicas & 42 & 40 \\
Ruestões rurais e de terras & - & - \\
Religião & - & - \\
Outros (datas comemorativas, homenagens, denominações) & - & - \\
Pessoas com deficiência & - & - \\
\hline
\end{tabular}




\begin{tabular}{c|c|c} 
Saúde & 4 & 4 \\
Segurança Pública & - & - \\
Trabalho & 2 & 2 \\
\hline Total & 104 & 100 \\
\hline
\end{tabular}

Fonte: Elaborada pela autora com dados do portal do Congresso Nacional. Acesso set. 2018.

A Tabela 7 indica que as áreas temáticas com maior número de projetos aprovados são outros (datas comemorativas, homenagens, denominações), com um percentual de $40 \%$ de proposições e cultura com $20 \%$ de proposições. As demais proposições aprovadas, um percentual de 40\%, concentram-se em áreas relacionadas tanto ao "cuidado" quanto a "bards", tais como: administração e serviço público, assistência social, código de trânsito, viação e transporte, código eleitoral, org. partidária, referendos e plebiscitos, código Penal e violências, criança e adolescente, economia, finanças e tributação, educação, esporte, gênero, idosos, pessoas com deficiência, questões rurais e de terras, saúde e trabalho. Apesar do baixo percentual de aprovação desses projetos, é importante destacar que essas matérias contemplam temas de áreas diversas, indicando que as deputadas estão atuando em diferentes agendas de trabalho.

O tema outros, que trata sobre datas comemorativas, homenagens e denominações, apresenta o maior percentual de proposições aprovadas. Quanto ao tema cultura, na primeira legislatura, nenhum projeto dessa área temática proposto com autoria feminina, foi aprovado. $\mathrm{Na}$ segundo legislatura, aprovou-se apenas o projeto número 2935/2008, que trata sobre a doação de bens de valor artístico, cultural e histórico aos museus.

$\mathrm{Na}$ terceira legislatura, foram vinte projetos aprovados sobre esse tema, o interessante que essas proposições se referem ao projeto número 4682/2012, o qual foi proposto em conjunto, por isso, este estudo considerou essa proposição para cada deputada que participou da sua elaboração e apresentação. O conteúdo desse projeto institui o Programa de Cultura do trabalhador e cria o vale-cultura, além de dar outras providencias. Outro ponto é o número de deputadas interessadas no tema, um total de 63 parlamentares sendo 44 homens e 19 mulheres envolvidos na autoria em conjunto da matéria, com destaque para Manuella D'Ávilla - PCdoB/RS e Jandira Feghali PCdoB/RJ como autoras principais da proposição com o deputado Paulo Rubem Santiago $\mathrm{PDT} / \mathrm{PE}$.

A tabela a seguir mostra o número de projetos arquivados por área temática. 
Tabela 8 - Projetos propostos pelas deputadas arquivados agregados das legislaturas por área

\begin{tabular}{|c|c|c|}
\hline Área temática dos projetos & $\begin{array}{l}\mathrm{N} \text { de Projetos } \\
\text { arquivados }\end{array}$ & $\%$ \\
\hline Administração e serviço público & 79 & 6 \\
\hline assistência Social & 32 & 2 \\
\hline Código Civil & 21 & 2 \\
\hline Código de Trânsito, viação e transporte & 60 & 5 \\
\hline $\begin{array}{l}\text { Código eleitoral, org. partidária, referendos e } \\
\text { plebiscitos }\end{array}$ & 27 & 2 \\
\hline Código Penal e Violências & 59 & 5 \\
\hline Comunicações e informática & 36 & 3 \\
\hline Consumidor & 16 & 1 \\
\hline Criança e adolescente & 64 & 5 \\
\hline Cultura & 9 & 1 \\
\hline Direitos humanos & 14 & 1 \\
\hline Economia, Finanças e Tributação & 100 & 8 \\
\hline Educação & 100 & 8 \\
\hline Esporte & 9 & 1 \\
\hline Gênero & 29 & 2 \\
\hline Idosos & 33 & 3 \\
\hline Meio Ambiente & 53 & 4 \\
\hline Minas e Energia & 9 & 1 \\
\hline Moradia & 9 & 1 \\
\hline Outros & 107 & 8 \\
\hline Pessoas com deficiência & 47 & 4 \\
\hline Questões Raciais e Étnicas & 5 & 0 \\
\hline Questões rurais e de terras & 36 & 3 \\
\hline Religião & 1 & 0 \\
\hline Saúde & 91 & 7 \\
\hline Segurança Pública & 46 & 4 \\
\hline Trabalho & 189 & 15 \\
\hline & 1281 & 100 \\
\hline
\end{tabular}

Fonte: Elaborada pela autora com dados do portal do Congresso Nacional. Acesso set. 2018.

A Tabela 8 indica que todas as áreas temáticas classificadas nesta pesquisa apresentam projetos arquivados, com destaque respectivamente para os seguintes temas: 15\% trabalho, 8\% outros (datas comemorativas, homenagens, denominações), 8\% economia, finanças e tributação, $7 \%$ saúde e $6 \%$ administração e serviço público.

Em relação ao percentual de projetos arquivados por áreas do "cuidado" e "hards”, 29\% de

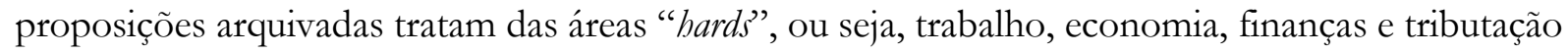
e administração e serviço público e $25 \%$ de proposições arquivadas abordam as áreas do "cuidado", isto é, educação, saúde, criança e adolescente e código penal e violência. 
As parlamentares apresentam um percentual equilibrado de projetos arquivados para ambas as áreas, sendo um fator positivo em relação a representação substantiva feminina, o que indica que elas estão mais atuantes em temas ditos masculinos e que essas proposições tramitam normalmente na Câmara Legislativa Federal, sem o estereótipo de que as mulheres atuam apenas em temas relacionados ao cuidado.

A tabela abaixo mostra o número de projetos por motivo de arquivamento, o interesse é identificar o motivo do arquivamento de $54 \%$ das proposições propostas pelas deputadas das legislaturas consideradas neste estudo.

Tabela 9 - Projetos propostos pelas deputadas arquivados agregados das legislaturas por motivo do arquivamento

\begin{tabular}{c|c|c}
\hline Motivo do arquivamento dos projetos & $\begin{array}{c}\text { N de Projetos } \\
\text { arquivados }\end{array}$ & $\begin{array}{c}\% \\
\%\end{array}$ \\
\hline Solicitado pelo autor do projeto & 84 & 7 \\
Fluído o prazo de recurso ao projeto & 53 & 4 \\
Ausência de reapresentação do projeto pelo autor & 64 & 5 \\
Projeto rejeitado na comissão & 148 & 12 \\
Projeto vetado na comissão ou em plenário & 7 & 1 \\
Projeto arquivado pelo fim da legislatura & 625 & 49 \\
Inconstitucionalidade e/ou injuricidade; inadequação financeira e & 15 & 1 \\
orçamentária do projeto & 285 & 22 \\
Projeto Prejudicado & 1281 & 100 \\
\hline Total & &
\end{tabular}

Fonte: Elaborada pela autora com dados do portal do Congresso Nacional. Acesso set. 2018.

Em relação ao total de proposições arquivadas, 49\% delas justificam-se pelo motivo fim da legislatura, conforme o artigo "Art. 105. Finda a legislatura, arquivar-se-ão todas as proposições que no seu decurso tenham sido submetidas à deliberação da Câmara e ainda se encontrem em tramitação, bem como as que abram crédito suplementar, com pareceres ou sem eles" (REGIMENTO INTERNO DA CÂMARA DOS DEPUTADOS, 1989, p. 59).

Ao final da legistura, todas as proposições submetidas à deliberação da Câmara, mas ainda em tramitação, são arquivadas, e podem ser desarquivadas por meio de requerimentos solicitados pelo autor ou autores da matéria, nos primeiros cento e oitenta da primeira sessão legislativa ordinária da legislatura subsequente, retomando a tramitação do estágio em que se encontrava. Este artigo não se aplica nos casos de proposições com pareceres favoráveis de todas as comissões já aprovadas em turno único, em primeiro ou segundo turno, que tenham tramitado no Senado, ou dele originárias, de inciativa popular, de iniciativa de outro Poder ou do Procurador-Geral da República. 
Conforme a Tabela 9, os demais motivos que justificam o arquivamento dos projetos propostos pelas deputadas, destaca-se $22 \%$ de projetos declarados prejudicados na comissão ou na plenária, sendo arquivados pelos seguintes artigos, "Art. 163. Da Proposição Prejudicada e arquivada definitivamente, quando considerada inconstitucional matéria idêntica a outra já aprovada ou rejeitada" e/ou Art. 164. Matéria pendente de deliberação pelo plenário ou comissão" (REGIMENTO INTERNO DA CÂMARA DOS DEPUTADOS, 1989, p. 77).

Logo, as proposições são consideradas prejudicadas em face da aprovação de outro projeto com igual conteúdo, ou em face da subemenda Substitutiva Global de Plenário ao projeto de lei, ou seja, uma emenda de forma a substituir integralmente a proposição principal, por isso, recebe o nome de substitutivo.

Há um percentual de 12\% dos projetos rejeitados na comissão, sendo arquivados pelo seguinte motivo:

Art. 133. A proposição que receber pareceres contrários, quanto ao mérito, de todas as Comissões a que for distribuída será tida como rejeitada e arquivada definitivamente por despacho do Presidente, dando-se conhecimento ao Plenário, e, quando se tratar de matéria retirada pelo Autor de proposição com parecer contrário, sem parecer (Regimento Interno da Câmara dos Deputados, 1989, p. 62).

E ainda os motivos com menor percentual de projetos arquivados: 7\% pelo artigo "114. Projeto retirado pelo interesse do autor", 5\% pelo artigo "104. Não ter uma nova apresentação pelo autor", 4\% pelo artigo “58. Fluído o prazo sem interposição de recurso"; 1\% pelo artigo “54. Inconstitucionalidade e/ou injuridicidade; inadequação financeira e orçamentária" e 0,5\% vetado na comissão ou em plenária. Apesar de um número considerável de proposições arquivadas, há um baixo percentual de projetos retirados pelas autoras. Também se observa o baixo percentual de proposições arquivadas por incapacidade técnica e proposições vetadas pela comissão ou em plenária.

A tabela a seguir mostra a associação entre área temática e tipo de autoria dos projetos de lei propostos pelas deputadas.

Tabela 10 - Projetos propostos pelas deputadas agregados das legislaturas por área temática e autoria

\begin{tabular}{|c|c|c|c|c|c|c|c|}
\hline \multirow{3}{*}{ Áreas temáticas } & \multirow{3}{*}{$\begin{array}{c}\mathrm{N} \text { de } \\
\text { projetos }\end{array}$} & \multicolumn{6}{|c|}{ Autoria } \\
\hline & & \multicolumn{2}{|c|}{ Autora } & \multicolumn{2}{|c|}{$\begin{array}{c}\text { Autora com } \\
\text { coautoria }\end{array}$} & \multicolumn{2}{|c|}{ Coautora } \\
\hline & & $\mathrm{N}$ & $\%$ & $\mathrm{~N}$ & $\%$ & $\mathrm{~N}$ & $\%$ \\
\hline Administração e serviço público & 134 & 122 & 91 & 5 & 4 & 7 & 5 \\
\hline Assistência Social & 68 & 59 & 87 & 6 & 9 & 3 & 4 \\
\hline Código Civil & 26 & 25 & 96 & - & - & 1 & 4 \\
\hline
\end{tabular}




\begin{tabular}{c|c|c|c|c|c|c|c} 
Código de Trânsito, viação e transporte & 95 & 87 & 92 & 8 & 8 & - & - \\
Código eleitoral, org. partidária, & 89 & 61 & 69 & 4 & 4 & 24 & 27 \\
referendos e plebiscitos & & & & & & & 4 \\
Código Penal e Violências & 112 & 98 & 88 & 10 & 9 & 4 & 4 \\
Comunicações e informática & 81 & 74 & 91 & 6 & 7 & 1 & 1 \\
Consumidor & 44 & 44 & 100 & - & - & - & - \\
Criança e adolescente & 123 & 115 & 93 & 5 & 4 & 3 & 2 \\
Cultura & 50 & 18 & 36 & 3 & 6 & 29 & 58 \\
Direitos humanos & 28 & 16 & 57 & 4 & 14 & 8 & 29 \\
Economia, Finanças e Tributação & 185 & 147 & 79 & 16 & 9 & 22 & 12 \\
Educação & 181 & 165 & 91 & 11 & 6 & 5 & 3 \\
Esporte & 21 & 17 & 81 & 1 & 5 & 3 & 14 \\
Gênero & 65 & 49 & 75 & 7 & 11 & 9 & 14 \\
Idosos & 55 & 55 & 100 & - & - & - & - \\
Meio Ambiente & 97 & 80 & 82 & 6 & 6 & 11 & 11 \\
Minas e Energia & 19 & 13 & 68 & 2 & 11 & 4 & 21 \\
Moradia & 12 & 12 & 100 & - & - & - & - \\
Outros & 192 & 171 & 89 & 11 & 6 & 10 & 5 \\
Pessoas com deficiência & 72 & 69 & 96 & 3 & 4 & - & - \\
Questões Raciais e Étnicas & 10 & 9 & 90 & 1 & 10 & - & - \\
Questões rurais e de terras & 46 & 30 & 65 & 7 & 15 & 9 & 20 \\
Religião & 4 & 1 & 25 & - & - & 3 & 75 \\
Saúde & 157 & 142 & 90 & 11 & 7 & 4 & 3 \\
Segurança Pública & 69 & 68 & 99 & 1 & 1 & - & - \\
Trabalho & 332 & 267 & 80 & 39 & 12 & 26 & 8 \\
\hline
\end{tabular}

Fonte: Elaborada pela autora com dados do portal do Congresso Nacional. Acesso set. 2018.

A Tabela 10 indica o percentual de projetos propostos por área temática e tipo de autoria. As deputadas propuseram um número considerável de projetos como única autora. Dessa maneira, identifica-se o percentual do total de projetos por área temática e única autora, assim destaca-se sobre esse tipo de autoria, $80 \%$ sobre o tema trabalho, $89 \%$ sobre o tema outros (datas comemorativas, homenagens e denominações), 79\% economia, finanças e tributações, 91\% educação, 90\% saúde, 91\% administração e serviço público, 93\% criança e adolescente e 88\% código penal e violências.

Em relação as demais áreas temáticas, também se evidenciam o considerável percentual de proposições propostas de única autora, do total de projetos apresentados sobre o tema assistência social $87 \%$ deles são de única autora, consumidor $100 \%$, esporte $81 \%$, gênero $75 \%$, idosos $100 \%$, moradia 100\%, questões raciais e étnicas $90 \%$ e segurança pública.

A tabela abaixo mostra a relação entre situação do projeto (arquivado, em tramitação, aprovado) e tipo de autoria. Conforme os dados a seguir: 
Tabela 11 - Projetos propostos pelas deputadas agregados das legislaturas por situação e autoria

\begin{tabular}{|c|c|c|c|c|c|c|c|}
\hline \multirow{3}{*}{ Situação } & \multirow{3}{*}{$\mathrm{N}$ de projetos } & \multicolumn{6}{|c|}{ AUTORIA } \\
\hline & & \multicolumn{2}{|c|}{ Autora } & \multicolumn{2}{|c|}{$\begin{array}{c}\text { Autora } \\
\text { com } \\
\text { coautoria }\end{array}$} & \multicolumn{2}{|c|}{ Coautora } \\
\hline & & $\mathrm{N}$ & $\%$ & $\mathrm{~N}$ & $\%$ & $\mathrm{~N}$ & $\%$ \\
\hline Arquivado & 1281 & 1157 & 90 & 66 & 5 & 58 & 5 \\
\hline Em tramitação & 982 & 789 & 80 & 91 & 9 & 102 & 10 \\
\hline Transformado em norma jurídica & 104 & 68 & 65 & 10 & 10 & 26 & 25 \\
\hline
\end{tabular}

Fonte: Elaborada pela autora com dados do portal do Congresso Nacional. Acesso set. 2018.

A Tabela 11 indica que os projetos em situação arquivado, 90\% deles são de única autora, $5 \%$ de autora com coautoria e 5\% de coautora. Os projetos em situação de tramitação, $80 \%$ de única autora, $9 \%$ de autora com coautoria e 10\% coautora. Em relação aos projetos propostos por autora com coautoria e por coautoria, em termo de percentual, apenas 10\% foram arquivadas, $19 \%$ tramitando em conjunto e 35\% transformados em normas jurídicas. Esses dados mostram que a autoria em conjunto tende a ser mais efetiva para as deputadas, quando comparado com o percentual de $90 \%$ de proposições, por autoria única, que foram arquivadas.

A tabela abaixo indica a relação entre o motivo do arquivamento e o tipo de autoria dos projetos propostos pelas deputadas, que na coleta de dados constavam como arquivados.

Tabela 12 - Projetos propostos arquivados pelas deputadas agregados das legislaturas por motivo do arquivamento e tipo de autoria

\begin{tabular}{|c|c|c|c|c|c|c|c|}
\hline \multirow{3}{*}{ Motivo do arquivamento } & \multirow{3}{*}{$\begin{array}{l}\mathrm{N} \text { de projetos } \\
\text { arquivados }\end{array}$} & \multicolumn{6}{|c|}{ TIPO DE AUTORIA } \\
\hline & & \multicolumn{2}{|c|}{ Autora } & \multicolumn{2}{|c|}{$\begin{array}{c}\text { Autora } \\
\text { com } \\
\text { coautora }\end{array}$} & \multicolumn{2}{|c|}{ Coautora } \\
\hline & & $\mathrm{N}$ & $\%$ & $\mathrm{~N}$ & $\%$ & $\mathrm{~N}$ & $\%$ \\
\hline Solicitado pelo autor do projeto & 84 & 78 & 93 & 5 & 6 & 1 & 1 \\
\hline Fluído o prazo de recurso ao projeto & 53 & 50 & 94 & 1 & 2 & 2 & 4 \\
\hline $\begin{array}{l}\text { Ausência de reapresentação do projeto pelo } \\
\text { autor }\end{array}$ & 64 & 58 & 91 & 5 & 8 & 1 & 2 \\
\hline projeto rejeitado na comissão & 148 & 128 & 86 & 11 & 7 & 9 & 6 \\
\hline Projeto vetado na comissão ou em plenário & 7 & 5 & 71 & - & - & 2 & 29 \\
\hline $\begin{array}{l}\text { Projeto arquivado pelo fim da legislatura } \\
\text { Inconstitucionalidade e/ou injuridicidade: }\end{array}$ & 625 & 595 & 95 & 20 & 3 & 10 & 2 \\
\hline $\begin{array}{c}\text { inadequação financeira e orçamentária do } \\
\text { projeto }\end{array}$ & 15 & 13 & 87 & 1 & 7 & 1 & 7 \\
\hline Projeto prejudicado & 285 & 230 & 81 & 23 & 8 & 32 & 11 \\
\hline
\end{tabular}

Fonte: Elaborada pela autora com dados do portal do Congresso Nacional. Acesso set. 2018. 
A Tabela 12 indica a relação entre motivo do arquivamento das proposições e o tipo de autoria delas. Evidencia-se que os motivos com maior número de projetos são arquivados pelo fim da legislatura, prejudicado, rejeitado na comissão e retirado por solicitação do autor do projeto. Em relação ao tipo de autoria das proposições arquivadas, verifica-se que mais de $80 \%$ das proposições de cada motivo em destaque são de única autoria.

Nesse contexto, independente do resultado da proposição, é importante considerarmos o debate promovido pelo projeto entre os parlamentares. Por isso, mesmo que um número considerável de matérias propostas, como autoria principal, pelas deputadas é arquivado, essas mulheres conseguiram de forma autônoma promover um debate em diversas áreas temáticas e consolidar a presença feminina no espaço político. Assim, consegue-se identificar para além do que elas fazem, mas também como elas atuam politicamente e o quanto são substantivas nesse espaço.

\section{CONCLUSÕES}

No caso brasileiro, há uma expressiva sub-representação feminina no parlamento. Por outro lado, as mulheres tendem a participar de movimentos e grupos sociais, como também atuar em partidos. Porém, o acesso à política ainda é limitado por questões culturais e familiares, desigualdade entre gêneros, entre outros aspectos que dificultam o aumento da presença feminina em cargos eletivos.

Nesse contexto, o processo representativo, a partir de uma representação substantiva que estimule a presença de novos interesses e opiniões, exige um maior engajamento político que pode ser promovido na participação em movimentos sociais e no associativismo. Conforme as pesquisas abordadas neste estudo, os interesses femininos são plurais e perpassam as mais variadas áreas como, violência, saúde, educação, entre outros. Dessa forma, os movimentos sociais e demais grupos são uma forma de aproximar a mulher da política.

As deputadas têm priorizado as áreas de economia, finanças e tributação e trabalho, o que torna interessante verificar quais as demandas dos grupos e movimentos de mulheres, isto é, quais as suas reivindicações e se essas pautas são inseridas pelas deputadas. Neste estudo, realizamos um mapeamento do que foi produzido em geral, estudos futuros podem investigar a conexão entre Estado e sociedade e verificar se as pautas de determinados movimentos feministas e grupos de mulheres estão sendo inseridas nas agendas parlamentares das deputadas e assim, identificar qual a aceitação no Legislativo. 
Assim, há um caminho a percorrer para superar a sub-representação feminina na política. Além das mulheres, há outros grupos minoritários que buscam uma representação substantiva. Dessa maneira, esta pesquisa avança na desmistificação dos estereótipos de que a mulher atua apenas em áreas maternas e do cuidado e que talvez não estão preparadas para o ambiente político. Elas estão sendo substantivas em seu desempenho parlamentar e buscam se envolver com a dinâmica do Parlamento. Por isso, a importância em fortalecer as políticas de incentivo à entrada feminina na política, pois o aumento no número de mulheres interfere na quantidade de projetos e nos seus desdobramentos no trâmite legislativo.

\section{REFERÊNCIAS}

ALMEIDA, C. C. R.; LÜCHMANN, L. H. H.; RIBEIRO, E. 2012. Associativismo e Representação Política no Brasil. Revista Brasileira de Ciência Política, Brasília, v. 8, p. 237-263, maioagosto.

ARAÚJO, C. 2001. As cotas por sexo para a competição legislativa: o caso brasileiro em comparação com experiências internacionais. Dados Revista de Ciências Sociais, Rio de Janeiro, v. 44, n. 001, p. 1-19.

ARAÚJO, C. 2009. Gênero e acesso ao poder no Brasil: as cotas entre as instituições e a cultura. Revista de Sociologia e Politica, Brasília, n. 2, p. 23-59, julho-dezembro.

AZEVEDO, D. B. 2013. Mulheres no Brasil: as conquistas legais e seus caminhos. In: Legislação da Mulher - Câmara dos Deputados, Edições Câmara, Brasília, $5^{\mathrm{a}}$ Edição, 402p.

AYRES, C. 2018. Quem são elas? - origens, carreiras e trajetórias políticas nas direções petistas. Florianópolis. Tese (Doutorado), departamento de Sociologia Política, Universidade Federal de Santa Catarina UFSC, 183 p.

CASTRO, S. I. 2007. Participação Feminina na Câmara dos Deputados: Um retrato da 50 Legislatura. Brasília. Monografia (Especialização em Processo Legislativo), Centro de Formação da Câmara dos Deputados. Biblioteca Digital da Câmara dos Deputados, 53p.

CAUL, M. 1999. Women's representation in Parliament: the role of political parties. Party Politics, London, v. 5, n. 1, p. 79.98.

CELIS, K.; CHILDS, S.; KANTOLA, J.; KROOK, M. L. 2008. Rethinking women's substantive representation. Representation, Abingdon, v. 99, n. 110, p. 2-44.

COTTA, M. 1998. Parlamento. In: BOBBIO, Norberto et al. Dicionário de Política. Brasília: ed. Unb, v. 1, p. 880.

DINIZ, S. 1999. Processo legislativo e sistema de comissões. Revista do Legislativo, Belo Horizonte: Assembleia Legislativa do Estado de Minas Gerais, n. 26, p. 60-78, abril-dezembro.

FIGUEIREDO, A.; LIMONGI, F. 1999. Executivo e Legislativa na Nova Ordem Constitucional. Rio de 
Janeiro: Ed. Fundação Getúlio Vargas.

FIGUEIREDO, E.C. dos S. 2011. Sistema de Comissões e o Poder Conclusivo na Câmara dos Deputados. Brasília. Especialização em Processo Legislativo, Centro de Formação da Câmara dos Deputados, Biblioteca Digital da Câmara dos Deputados, 42 p.

FRANCESCHET, S. 2008. Promueven las cuotas de Género los intereses de las mujeres? El impacto de las cuotasen la representación sustantiva de las mujeres. In: TOBAR, M. R. (ed.). Mujer Y Política: el impacto de las cuotas de gênero en América Latina. $1^{\mathrm{a}} \mathrm{ed}$. Santiago, Chile: Catalonia.

INTER-PARLIAMENTARY UNION (IPU). 2016. Relatório sobre Mulheres no Parlamento. Disponível em: https://www.ipu.org/news/press-releases/2017-03/. Acesso em 3 jul. 2019.

INTER-PARLIAMENTARY UNION (IPU). 2019. Women in national parliaments. Disponível em: http://www.ipu.org/wmn-e/classif.htm em 1 fev. 2019. Acesso em 03 de julho de 2019.

KARLINSKI, E. 2012. Gênero na Câmara Legislativa do Distrito Federal: Um olhar sobre a ação parlamentar feminina. Brasilia. Monografia (Especialização em Processo Legislativo), Centro de Formação da Câmara dos Deputados. Biblioteca Digital da Câmara dos Deputados, 151p.

MANSBRIDGE, J. 2005. Quota Problems: Combating the Dangers of Essentialism. Politics and Gender, Cambridge, v. 1, n. 4, p. 622-638.

2003. Rethinking Representation. American Political Science Review, Cambridge v. 97, n. 4, p. $515-528$.

1999. Should Blacks Represent Blacks and Women Represent Women? A Contingent Yes. Journal of Politics, University of Texas Press, v. 61, n. 3, p. 628-657.

MARTINS, E. V. 2007. A Política de Cotas e a Representação Feminina na Câmara dos Deputados. Brasília. Monografia (Especialização em Processo Legislativo), Centro de Formação da Câmara dos Deputados, Biblioteca Digital da Câmara dos Deputados, 58p.

MÉNDEZ, E. G. 2019. Representación política de las mujeres en los Congresos subnacionales en México. Um modelo de evaluación. Estudos Políticos, Ciudad de México, n. 46, p. 73-98, janeiroabril.

MOTTA, B. K. 2016. Participação Política das Mulheres na Câmara Federal Brasileira nas 52a $53^{a}$ e $54^{a}$ Legislaturas. Brasília. Monografia (Especialização em Processo Legislativo), Centro de Formação da Câmara dos Deputados, Biblioteca Digital da Câmara dos Deputados, 123p.

NONATO, F. J. A. P.; PEREIRA, R. H. M.; NASCIMENTO, P. A. M. M.; ARAÚJO, T. C. 2012. O Perfil da Força de Trabalho Brasileira: trajetórias e perspectivas. Mercado de trabalho, Nota Técnica IPEA - Instituto de Pesquisa Econômica Aplicada, Brasília, n. 51, p. 29-41.

PAIVA, D.; HENRIQUE, A. L.; SILVA, G. P. 2013. Atuação das mulheres no Poder Legislativo Federal e Estadual e no Brasil: ainda muito distante da paridade de gênero. Cadernos Adenauer, Novas Perspectivas de Gênero no Século XXI, Rio de Janeiro. p.167- 182. 
PHILLIPS, A. 2001. De uma política de ideias a uma política de presença? Revista Estudos Feministas, Florianópolis, v. 9, n. 1, p. 268-290.

PINHEIRO, L. S. 2006. Vozes femininas na política: uma análise sobre mulheres parlamentares no pósConstituinte. Brasília. Dissertação (Mestrado) - Departamento de Sociologia, Universidade de Brasília, 2006. 248 p.

PITKIN, H. 2006. Representação: palavras, instituições e ideias. Lua Nova, São Paulo, n. 67, p.1547.

The concept of representation. 1972. University of California Press, London, Englad.

POST, T. F. 2015. Representação substantiva de mulheres na Câmara dos Deputados. Brasília. Monografia (Especialização em Processo Legislativo), Centro de Formação da Câmara dos Deputados, Biblioteca Digital da Câmara dos Deputados, 72p.

United Nations Development Programme. 2018. Human Development Indices and Indicators 2018. Communications Development Incorporated, Washington DC, USA 1 UN Plaza, New York.

PRINCE, E. G. 2007. Sentido y contenidos de la construcción de una agenda legislativa para el desarrollo de los derechos de las mujeres. Contenido, Managua.

RIBEIRO, P. J. F. 2008. Dos sindicatos ao governo: a organiz̧ação nacional do PT de 1980 a 2005. São Carlos. Tese (Doutorado), Departamento de Ciência Política, Universidade Federal de São Carlos, $307 \mathrm{p}$.

RIBEIRO, P. J. F. 2013. Organização e Poder nos partidos brasileiros. Revista Brasileira de Ciência Politica. Brasília, n. 10, p. 225-265, janeiro-abril.

RODRIGUES, A. Participaşão politica das mulheres e gestão em política de gênero. Brasília, 2004. Disponível em: <http://www.cfemea.org.br>. Acesso em 25 jan. 2015.

SACCHET, T. 2009. Capital Social, gênero e representação política no Brasil. Opinião Pública, Campinas, v. 15, n. 2, p. 306-332, novemvro.

SCHWINDT-BAYER, L. A.; MISHLER, W. 2005. An Integrated Model of Women's Representation. The Journal of Politics, Chicago, v. 67, n. 2, p. 407-428, may.

SANCHEZ, B. R. 2015. Quem são e o que fazem as parlamentares brasileiras? Uma análise do perfil. I Seminário Internacional de Ciência Política, Universidade Federal do Rio Grande do Sul, 9 a 11 de setembro.

SILVA, A. P. C. L. 2015. Os efeitos do associativismo no desempenho parlamentar feminino. Maringá. Dissertação (Mestrado), Departamento de Ciências Sociais, Universidade Estadual de Maringá, Paraná, 60 p. 
SOW, M. M. 2009. A Participação Feminina na Construção de um Parlamento Democrático. Brasília. Monografia (Especialização em Processo Legislativo), Centro de Formação da Câmara dos Deputados, Biblioteca Digital da Câmara dos Deputados, 50p.

TRIBUNAL SUPERIOR ELEITORAL (TSE). Estatística do eleitorado. Disponível em: http://www.tse.jus.br. Acesso em 20 mar. 2019.

URBINATI, N. 2006. O que torna a representação democrática. Lua Nova, São Paulo, v. 67, p. 191-228.

URBINATI, N. 2006. Representative Democracy: Principles \& Genealogia. Chigaco Press, 2006.

WARREN, M. E. 2006. Rethinking Democratic Representation: Eight Theoretical Issues. Centre for the Study of Democratic Institutions University of British Columbia.

YOUNG, I. M. 2006. Representação política, identidade e minorias. Lua Nova, São Paulo, v. 67, p. 139-190. 